\title{
ACQUIRED CROSSED RENAL ECTOPIA SECONDARY TO A GIANT RENAL CYST
}

\author{
SIANLEY J. SWIERZEWSKI, III, M.D. \\ HUGH D. FLOOD, M.D. \\ H. BARION GROSSMAN, M.D.
}

From the Department of Surgery, Section of Urology, University of

Michigan Medical Center, Ann Arbor, Michigan

\begin{abstract}
We report a case of contralateral renal displacement due to a giant ipsilateral renal cyst. Drainage and partial excision of the cyst was followed by return of the kidney and liver to their normal positions. Incidentally, a small focus of renal cell carcinoma was found after pathologic examination of the cyst wall. The relevant literature is reviewed.
\end{abstract}

Kidney displacement resulting from renal cysts are rare. Three cases of contralateral displacement of the kidney by an ipsilateral renal cyst have been reported previously, ${ }^{1,2}$ and only one report describes the findings and follow-up in detail, demonstrating return of the kidney to its normal position on excretory urogram following treatment. ${ }^{1}$ Other authors have described varying degrees of renal displacement in relation to enlargement of neighboring organs or benign retroperitoneal tumors and have noted the association of extreme displacement with nonmalignant processes. . $^{3-5}$

The reported incidence of carcinoma and renal cysts in the same kidney ranges between 0.5 percent and 7 percent. ${ }^{6-11}$ The incidence of renal carcinoma in people with end-stage renal failure and acquired cystic kidney disease is 1 percent. ${ }^{12}$ The incidence of microscopic renal neoplasm arising anywhere within the wall of a solitary cyst is probably much lower and has been reported rarely, ${ }^{9,13-20}$ The role of local excision as definitive therapy for a renal cyst containing a carcinoma remains controversial. We report an unusual case of extreme renal displacement to the contralateral side by a renal cyst containing a microscopic focus of renal adenocarcinoma.

\section{CASE REPORT}

A fifty-one-year-old man was referred with a history of a single episode of gross hematuria and a

Submitted: July 30, 1993, accepted (with revisions): September 14,1993 gradually increasing abdominal swelling. His medical history was significant for blunt abdominal trauma from a motor vehicle accident thirtyseven years previously which had been managed

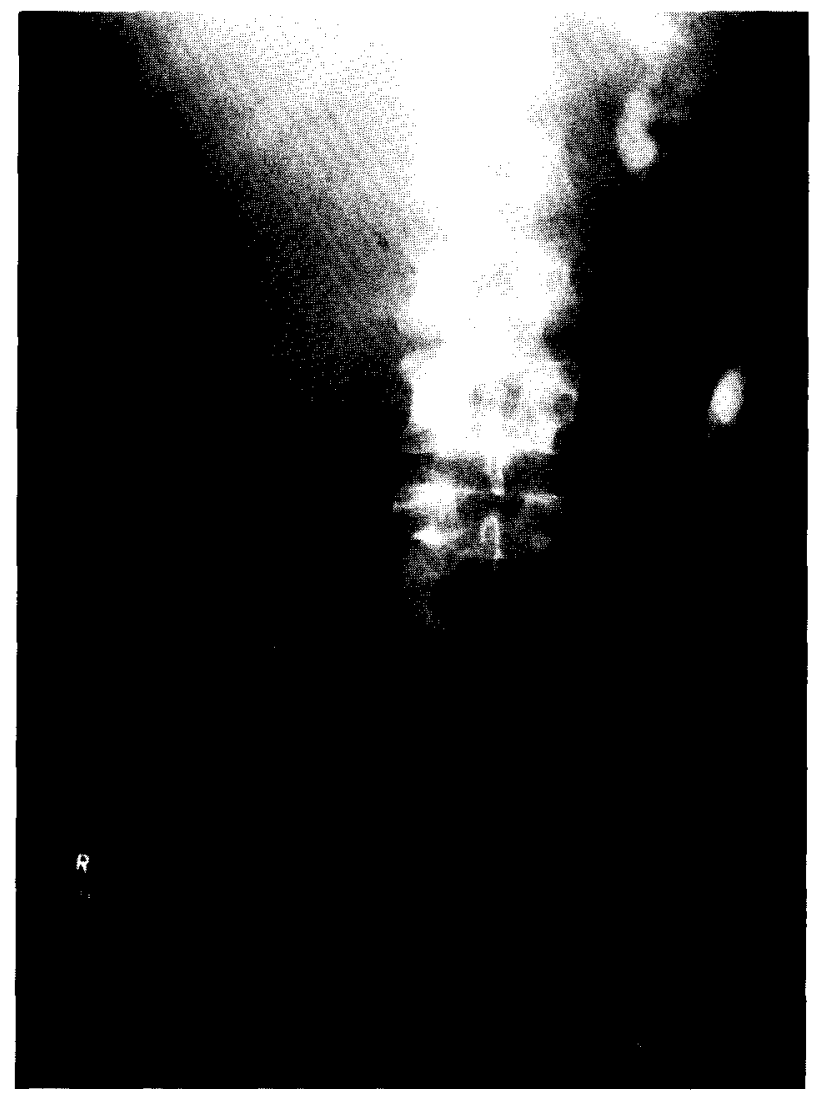

FIGURE 1. Intravenous urography suggesting an abdominal soft tissue mass with right to left crossed, nonfused renal ectopia. 
with several days of observation in hospital. At the time of the current referral, findings on urinalysis, urine cytology, and cystoscopy were all negative.

Intravenous urography demonstrated a huge, right-sided, abdominal soft tissue mass with right to left crossed, nonfused renal ectopia (Fig. 1). Computed tomography (CT) demonstrated a large fluid-filled structure displacing the abdominal contents to the left (Fig. 2). The cyst was solitary and arose from the right kidney which appeared to be splayed open along the cyst wall (Fig. 3A). The contents of the cyst were homogenous and of low attenuation, consistent with a simple renal cyst.

Exploration was elected to decompress the cyst and excise as much of the cyst wall as possible in an effort to prevent recurrence. Because of the massive size of the cyst endoscopic techniques were not considered. A midline incision was used to provide maximum flexibility in surgical exploration. The cyst was decompressed and then opened anteriorly. The cyst was unilocular and filled with $12 \mathrm{~L}$ of clear fluid. The subcapsular renal surface was visible at the base. The posterior wall of the cyst covered most of the retroperitoneum. The inner surface of the cyst was trabeculated, and many small, yellow plaques were seen. There was no evidence of tumor. Administration of indigo carmine indicated no communication between the renal collecting system and the cyst. Creatinine level in the cyst fluid was equal to that of serum. Cytologic examination for tumor was negative. The anterolateral cyst wall was excised. Pathologic examination of the specimen revealed a hamartomatous renal cyst with one small focus

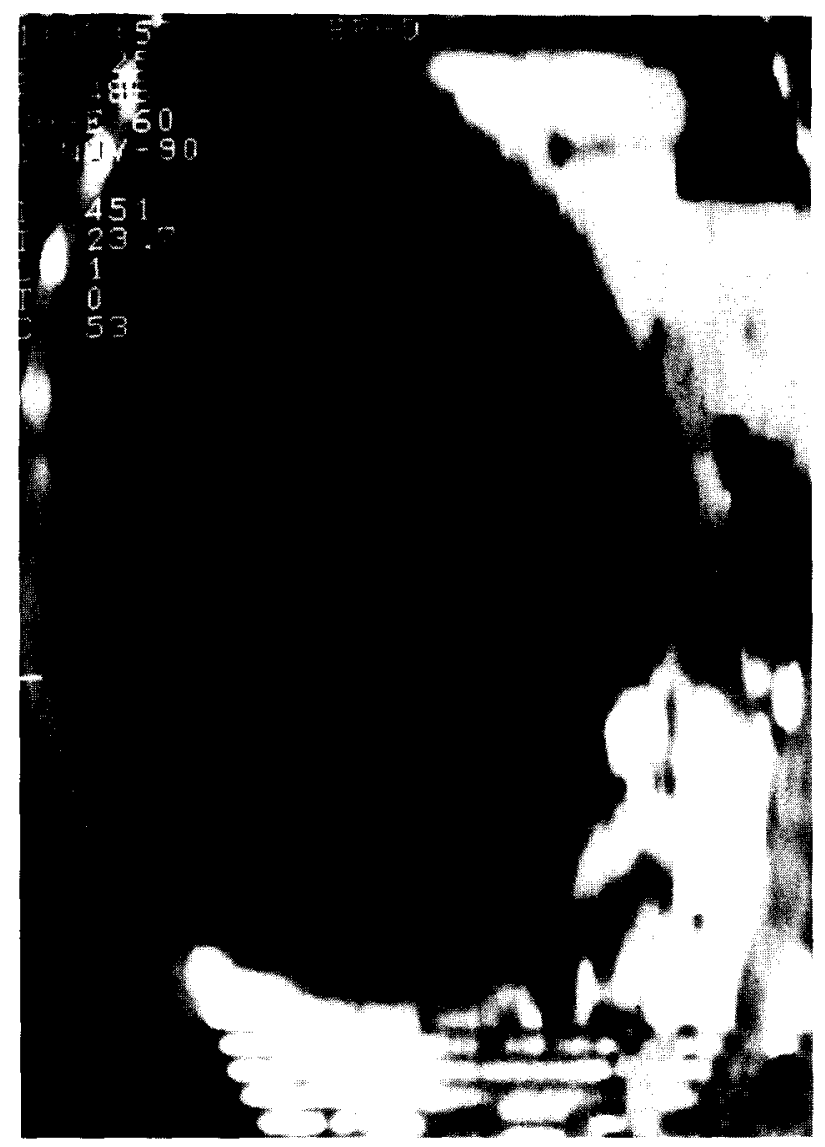

FIGURE 2. Coronally reconstructed computed tomography (CT) demonstrating a large fluid-filled structure displacing the abdominal contents to the left.

of clear cell adenocarcinoma (Fuhrman grade I) in the free wall of the cyst.

A CT scan two months postoperatively showed return of the liver, kidney, and other organs to their anatomic positions (Fig. 3B) with good right

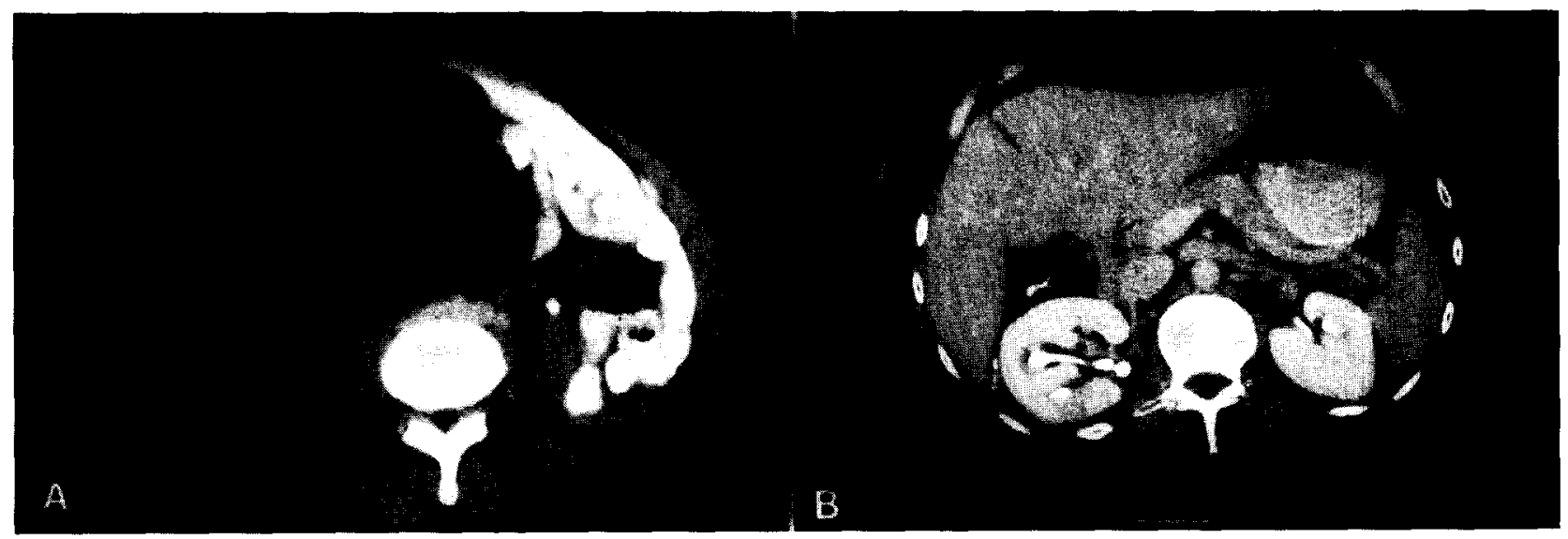

FIGURE 3. (A) Computed tomography (CT) demonstrating the right kidney which appeared to be splayed open along the cyst wall. (B) Postoperative CT showing return of the liver, kidney, and other organs to their anatomic positions. 
renal function. Nephrectomy for possible residual tumor was considered. However, close observation was elected because of the microscopic and focal nature of this tumor. Follow-up CT examinations have demonstrated no evidence of cyst or tumor recurrence thirty-one months postoperatively.

\section{COMMENT}

This case illustrates two notable, if unusual, features of solitary renal cysts. The first is the ability of these cysts to grow to a very large size, sufficient to displace the functioning kidney to the opposite side. The second is the finding of incidental carcinoma in the free wall of the cyst. Giant solitary renal cysts giving rise to a form of acquired, crossed renal ectopia are rare. ${ }^{1,2}$ These cases are distinguished by a relative lack of symptoms, in association with a large abdominal mass, preservation of normal renal function despite extreme displacement, and the ability of intra-abdominal anatomy to return to normal following surgical decompression and cyst excision. ${ }^{2}$ As has been noted previously, this set of circumstances is usually attributable to slow displacement over many years by a benign process. ${ }^{5,21}$ Some degree of renal displacement is a common feature of retroperitoneal tumors, being seen in 70 percent of these cases. ${ }^{3.4}$ Extreme displacement (to the opposite side) has been reported with benign tumors such as lipoma, adrenal cyst, retroperitoneal cyst, cystic fibroma, and also with low-grade fibrosarcoma. ${ }^{5}$ Complete cyst excision may be difficult if not impossible because of adherence of the cyst wall to the retroperitoneal structures. Decompression and partial excision are reasonable alternatives if the cyst and cyst fluid have no malignant features. Uneventful return of the displaced organs to their normal anatomic location seems to be a constant feature. ${ }^{2.5 .21}$

The finding of incidental renal cell carcinoma in the free wall of a unilocular renal cyst is very rare. ${ }^{9,13-20}$ Carcinoma has never been reported in the case of a giant renal cyst (i.e., one which displaces the kidney to the opposite side). Radiologically, based on computed tomography, the cyst in our case would be defined as category I and therefore, benign." In 1954, Gibson ${ }^{6}$ suggested a classification to describe the association of renal cysts and renal carcinoma: (1) tumor and cyst in opposite poles of the kidney; (2) cystic degeneration within a tumor; (3) tumor arising in the wall of a cyst; and (4) cyst peripheral to tumor, i.e., tumor in the parenchymal base of the cyst. Our case falls into category 3, although Gibson ${ }^{6}$ doubted the existence of this entity. Furthermore, of 1,007 cases of surgically explored renal cysts at the Mayo Clinic, there were no cases of tumor in the free wall of a serous cyst, ${ }^{9}$ and these authors also doubted the existence of such an entity. There are now 6 reported cases (including ours) of tumor arising in the free wall of a simple renal cyst which seem to fulfill Gibson's category 3 classification. ${ }^{15-18,23}$ In one of these cases, the tumor was multifocal within the cyst and could therefore have arisen at the base. ${ }^{17}$ Tumors arising in the cyst base closely associated with the parenchyma (Gibson 4) may be more common and the association of the two can be explained experimentally by a combination of ischemia and tubular obstruction. ${ }^{24} \mathrm{Un}$ fortunately, renal vein invasion ${ }^{15}$ and subsequent metastatic disease ${ }^{18}$ have been described in 2 of the 6 cases referred to previously so that tumor arising in the free wall of a renal cyst cannot be assumed to act in a benign fashion. Of note is the fact that one of these tumors was less than $2 \mathrm{~cm}$ in diameter, ${ }^{15}$ and in the other case the patient was treated with partial nephrectomy despite preoperative evidence of malignant cyst fluid cytology. In our case, the finding of microscopic carcinoma was completely incidental to the management of the huge renal cyst and only discovered postoperatively. The election of observation rather than nephrectomy was based on the focal nature of the tumor, and the documented excellent results with local excision of renal carcinomas. ${ }^{25-27}$

\section{H. Barton Grossman, M.D. Department of Surgery Section of Urology \\ University of Michigan Medical Center 1500 East Medical Center Drive Ann Arbor, Michigan 48109}

Acknowi.fDGmFnts. To Ms. Carrie Griffith for her patience, diligence, and editorial input in the preparation of this manuscript.

\section{RFFERFNCES}

1. Wesson MB: Urologic Roentgenology, Lea \& Febiger, Philadelphia, 1966, p 76.

2. Woesner ME, Lang DW, and Selvaggi FP: Contralateral displacement of the kidney by solitary renal cyst. Am J Roentgenol Radium Ther Nucl Med 116: 766-772, 1972.

3. Schulte TL, and Emmett JL: Urography in differential diagnosis of retroperitoneal tumors. J Urol 42: 215-219, 1939.

4. DeWeerd JH: Lipomatous retroperitoneal tumors: urographic findings. J Urol 71: 421-426, 1954.

5. Engel WJ: The significance of renal displacement. J Urol 76: 478-487, 1956

6. Gibson TE: Interrelationship of renal cysts and tumors: report of three cases. J Urol 71: 241-252, 1954.

7. Brannan $W$, Miller $W$, and Crisler $M$ : Coexistence of 
renal neoplasms and renal cysts. South Med 1 55: 749-752, 1962 .

8. Emmetl JL, Levine SR, and Woolner LB: Co-existence of renal cyst and tumour incidence in 1,007 cases. Br J lirol 35: 403-410, 1963

9. Levine SR, Emmett Jl, and Woolner LB: Cyst and tumor cocurring in the same kidney. J Urol 91: 8-9, 1964.

10. Weiss H. Ludwig G, Weiss A, Keller W, Rethel R, Sommer $W$, and Busing $C M$ : Frequency of kidney cyst wall cancer-results of 22,000 ultrasound studies. Ultraschall Med 4: $2+-30,1983$

11. Bliemeister $\mathrm{H}$, and Seppelt $U$ : Cancer of a renal cyst wall. Z Urol Nephrol 78: 289-291, 1985.

12. Chandhoke PS, Torrence RJ, Clayman RV, and Rothstein $\mathrm{M}$ : Acquired cystic disease of the kidney: a manage ment dilemma. J Urol 147: 969-974, 1992.

13. Khorsand D: Carcinoma within solitary renal cyst. I Urol 93: $440-444,1965$.

14. Silverman JF, and Kilhenny C: Tumor in the wall of a simple renal cyst. Report of a case. Radiology 93: 95-98, 1969.

15. Weitzner S: Clear cell carcinoma of the free wall of a simple renal cyst. J Urol 106: 515-517, 1971 .

16. Srimannarayana A, Kelly DG, and Duff FA: Renal cell carcinoma in the free wall of a simple renal cyst. Br J Urol 47: 152, 1475

17. Sulrin G, Etra W. Gaeta J, and Merrin CE: Hycrmephroma arising in wall of simple renal cyst. Urology 6 : $507-510.1975$
18. Bruun $\mathrm{E}$, and Nielsen $\mathrm{K}$ : Solitary cvst and clear cell adenocarcinoma of the kidney: report of 2 cases and review of the literature. J Urol 136: 449-451, 1986.

19. Nishibuchi S, Suzuki $Y$, and Okada $k$ : A case report of renal cell carcinoma in a renal cyst. Hinyokika Kiyo 38: $181-184,1992$.

20. Ljungberg $B$, Holmberg $G$, Sjodin $K$, Hietala $\$ O$, and Stenling R: Renal cell carcinoma in a renal cyst: a case report and review of the literature. I Urol 143: 797-799, 1990.

21. Greene LF: Extreme renal displacement due to retroperitoneal tumors. J Urol 59: 174-178, 1948

22. Bosniak MA: The current radiological approach to renal cysts. Radiology 158: 1-10, 1986.

23. Sarma DP, Weibaecher TG, and Waggenspack GA: Renal cell carcinoma presenting as a single large cyst. J Surg (oncol 32: 30-31, 1986.

24. Hepler AR: Solitary cysts of the kidney: A report of seven cases and observations on the pathogenesis of these cysts. Surg Gynecol Obstet 50: 668-687, 1930.

25. Novick AC, Zincke H, Neves RJ, and Topley HM: Surgical enucleation for renal cell carcinoma. I L/rol 135: 235-238, 1986.

26. Topley M. Novick AC, and Montie JE: Long-term results following partial nephrectomy for localized renal adenocarcinoma. J Urol 131: 1050-1052, 1984.

27. Moll $V$, Becht $F$, and Ziegler $M$ : Kidney preserving surgery in renal cell tumors: indications, techniques and results in 152 patients. J Urol 150: 319-323, 1993 